\title{
THE LADD FRANKLIN HYPOTHESIS OF COLOUR VISION
}

\author{
BY \\ H. Hartridge, M.D., Sc.D. \\ FELLOW OF KING'S COLLEGE, CAMBRIDGE
}

As the incompatibilities of the Hering and Young hypotheses of colour vision became more obvious, there occurred to more than one experimenter the idea of devising some intermediate theory which would avoid the pitfalls which the older hypotheses appeared to have encountered. In this way the theories of McDougall, Schenck, and others came into being. Mrs. Ladd Franklin's hypothesis may be quoted as another example. She regards the fundamental and essential feature of the Young hypothesis to be the fact that all known shades of colour can be matched by mixtures of the three pure spectral colours-red, green and blue. As the fundamental fact of the Hering theory she regards the existence of " opposite" pairs of colours, red and green, yellow and blue, black and white. On this foundation she erects the following structure :-

There was initially in the earliest stage of development of the organ of vision but one sensation-that aroused by white light and its negation. This underwent gradual elaboration, first into two sensations, one of short wave length, blue light, and the other into long wave length, yellow light. Later, a further elaboration of the yellow sensation occurred by its partial differentiation into sensations for green and red. So that we have present in the foveal cones of normal-sighted individuals, according to Mrs. Ladd Franklin, five sensations, those for white, blue, yellow, red and green. In the periphery of the normal-sighted retina, and in the fovea of certain colour-blind persons, the process of development has not been completed-that is, that in her opinion colour blindness is atavistic.

Having thus briefly stated the theory, I propose to discuss three things :-

1. Its ability to fit in with all the known facts of colour vision.

2. Its novelty; and

3. Its utility.

The first point which comes up for consideration is the compatibility of the hypothesis with the duplicity theory of von Kries, because, rightly or wrongly, I regard this to be the touchstone on which all existing colour theories should first be tried, before other tests are applied to them. This ordeal Mrs. Ladd Franklin's 
theory passes successfully, because she states that the recognition of a rod mechanism for night vision and a cone colour sensitive mechanism for day vision "was, of course, a fundamental and essential part of it from the beginning."

The facts of colour vision are explained by the theory as follows :-

Suppose, in the first place, that white light falls on the retina, the white-black substance is decomposed and its breakdown products stimulate the cones, arousing a sensation of white light. If the light be blue, breakdown products corresponding to blue light are alone present and a sensation of blue results. If yellow light be concerned instead, a similar process causes a yellow sensation. If both blue and yellow light fall on the same part of the retina, the breakdown products corresponding to both are present, and they combine to reform the mother-substance from which they were first differentiated, and this stimulates the cones with a sensation of white light. If more of one substance is present, e.g., the blue one, a bluish white light will result and vice versâ. In a similar manner red and green, when present alone, stimulate the corresponding sensations, but when present together the breakdown products which they produce recombine to form the yellow substance, and thus a sensation of yellow light results. If red, green and blue lights be all three present simultaneously, first the breakdown products produced by the red and green light re-combine to form the yellow product, and then this combines with the product formed by the blue light to form the original substance which stimulates the white sensation.

Colour-blindness is accounted for by a partial or complete deficiency of one of the photo-chemical substances, or by an abnormality in the absorption curve of one or more of them, as is the case with Young's theory.

Mrs. Ladd Franklin has elaborated her theory so that it will make a show of accounting for the main facts of simultaneous and successive contrast. We need not, however, go further into these matters because it is now established, almost beyond dispute, that while colour vision depends on peripheral analysis, i.e. in the retina, simultaneous and successive contrast are due to processes of central origin, i.e. in the brain. It is not therefore necessary for any hypothesis which is supposed to represent the peripheral processes to offer an explanation of contrast as well.

Lastly, we come to peripheral vision. Now, since according to Mrs. Ladd Franklin's theory, the red and green sensations are both developed from the more primitive yellow, we should expect the sensation of red and green to be found beginning together at one and the same retinal boundary, as one passes the test stimuli 
from the extreme colour defective periphery towards the centre of the retina with its full colour perception. The most recent work on peripheral vision, that of Ferree and Rand, in America, shows that with test lights of equal intensity, but different colour, the blue, yellow and red sensations occur together over a considerable area, but that the green sensation is found to occur over a considerably smaller one. Now it is well known that the eye suffers from both chromatic difference of focus and chromatic difference of magnification. Assuming that the latter has a magnitude in the case of the eye equal to that of a mass of water of the same approximate optical properties, Gullstrand calculated that blue rays would form images whose distance from the optical centre of the retina (where the optic axis cuts the retina) would be 3 per cent. greater than the distances from the centre for the images produced by red rays. That is, that in order that a blue ray and a red one should enter the eye and fall on the same point of the retina, the angle that the blue ray made with the optical axis would have to be roughly 3 per cent. greater than that made by the red ray. It is not stated in Ferree and Rand's paper whether they have taken this factor into account when they say that blue, yellow and red stimuli commence to be correctly recognized at the same angle with the optical axis. This, however, is a matter of detail; what is clear is that red stimuli are recognized at much greater angles than are green, whereas, according to Mrs. Ladd Franklin, they should occur together (with a possible 1 or 2 per cent. greater angle in the case of green owing to the chromatic aberration of the eye).

This would appear to be a fundamental objection to the theory. It may be that Mrs. Ladd Franklin can modify, or has already modified, her theory so that it avoids this difficulty. In that case the writer must offer his apologies.

The questions which remain to be considered concern the novelty and the utility of the theory. With regard to the former, Parsons has written that Mrs. Ladd Franklin's theory " perhaps owes more than she would readily admit to Donders' theory." Now Donders accepted three fundamental colours-red, green and blue, but for colour sensations-red, yellow, green and blue, which, with a sensation of white, make the same five sensations as Mrs. Ladd Franklin postulates. There are many other points of similarity. Thus Donders stated in 1881 that from the combined chemical dissociations produced when both red and green light fall on the retina, a third colour-yellow-can arise. So, also, complete dissociation is stated to produce " white," while partial dissociations produce colours. Practically identical statements have been made by Mrs. Ladd Franklin, twelve years later, in 1893. We may say then that Donders' older theory bears a very 
strong likeness to the one under consideration. Whether it anticipates all the fundamental points or not turns largely on the precise interpretation to be put on certain sentences, and need not be further discussed here.

In considering the advantages of this theory over others, we have, first, to determine whether it more readily fits the observed facts than do the others. Now Young's theory, while explaining the fact that all colours can be matched by a mixture of three primaries, also as readily explains the existence of complementary colours in spite of the statement to the contrary that Mrs. Ladd Franklin has made. The facts of simultaneous and successive contrast were once serious pitfalls to it, but they are so no longer because it is not necessary for a theory concerning processes taking place in the retina, to offer also explanations of processes occurring in the brain. An altogether separate theory must one day be elaborated to deal adequately with these processes. McDougall and Sherrington have pointed out the road; it will be the lot of some future physiologist to follow that road to its destination.

The various types of the colour-blind are also adequately dealt with by Young's theory. Where the theory fails is in its dealings with peripheral vision. How can it explain why green drops out, while yellow, red and blue sensations persist into the extreme periphery? Can it be that the maximum of the green sensation curve shifts towards the red to such an extent that a " neutral" band exists where green should be represented? We do not know. What we do know is that the last word on peripheral vision has yet to be written, in spite of the excellent work of Abney and of Ferree and Rand, and others. In this connection, then, Young's theory fails us and Mrs. Ladd Franklin's theory, in spite of its greater elaboration, is no more certain a guide.

Lastly, we may apply that most searching test which any theory can face, namely, its achievements in initiating research and in indicating new facts of colour vision. Has Mrs. Ladd Franklin's theory led to work comparable with that performed by Maxwell, Abney and Watson under the stimulus of Young's theory?

\section{REFERENCES}

1. Zeitschr. f. Psychol. u. Physiol. d. Sinnesorgane, Vol. IV, p. 211, 1893.

2. Mind, N.S., Vol. II, p. 473, 1893.

3. Science, Vol. LV, May, 192 2.

4. The Psychological Review, Vol. XXIX, p. 180, 1922. 